\title{
Profile of Asphyxiated Babies at Tribhuvan University Teaching Hospital
}

\author{
Shrestha $\mathbf{M}^{1}$, Shrestha $\mathbf{L}^{2}$, Shrestha $\mathbf{P S}^{3}$ \\ ${ }^{1}$ Dr. Merina Shrestha, MBBS, MD. (Teaching Assistant), ${ }^{2}$ Dr. Laxman Shrestha, MBBS, MD. (Associate Professor), \\ ${ }^{3}$ Prof. Prakash Sundar Shrestha. All from the Neonatal Division, Department of Pediatrics, Tribhuvan University \\ Teaching Hospital, Institute of Medicine, Maharajgunj, Kathmandu, Nepal.
}

Address for Corresspondence: E-mail: shresthamerina@hotmail.com

\begin{abstract}
Objective: To assess risk factors and outcome in the early neonatal period of babies who were asphyxiated at birth. Methodology: This was a retrospective study conducted at Tribhuvan University Teaching Hospital (TUTH) over a period of one year from $15^{\text {th }}$ Feb 2007 to $14^{\text {th }}$ Feb 2008. All the term babies who had Apgar score of less than $\leq 6$ at 1 minute of birth were included. Detailed maternal risk factors during pregnancy and labor were analyzed. The newborn babies who required admission in neonatal unit were again analyzed for development of hypoxic ischemic encephalopathy (HIE) and their outcome. Results: During the study period, out of 3594 term babies, 327 babies (9\%) were asphyxiated. Of the total asphyxiated babies, $85 \%$ and $15 \%$ had moderate and severe asphyxia, respectively, at 1 minute of birth. Out of these asphyxiated babies, $51 \%$ and $7 \%$ had intrapartum and maternal risk factors, respectively. Intrapartum risk factors like meconium stained liquor, non-vertex presentation, and fetal heart rate abnormalities accounted for 4 fold risk of asphyxia. Of these babies, $26 \%$ required admission in nursery and 29\% developed hypoxic ischemic encephalopathy. Among the admitted babies $6 \%$ expired, $2 \%$ left against medical advice and rest were discharged. Conclusion: Early identification and close monitoring of high risk mothers studies with maintaining partograph during labor will help to reduce neonatal asphyxia.
\end{abstract}

\section{Key words:}

\section{Introduction}

Birth asphyxia is a serious clinical problem worldwide. Each year approximately 4 million babies are born asphyxiated, which results in 1 million deaths and an equal number of serious neurological sequaele, such as cerebral palsy, mental retardation, and epilepsy. ${ }^{1}$ Asphyxia is an insult to the fetus or newborn due to lack of oxygen or lack of perfusion to various organs. ${ }^{2}$ There are many reasons a baby may not be able to take in enough oxygen before, during or just after birth. A mother may have medical conditions that can lower her oxygen levels; there may be problem with the placenta that prevents enough oxygen from circulating to the fetus; or the baby may be unable to breath after delivery. In leading hospitals of Kathmandu, it is seen that birth asphyxia is responsible for 5 to $30 \%$ of neonatal mortality and morbidity. ${ }^{3}$ An unpublished data from TUTH has shown that the incidence of birth asphyxia is almost constant over the past 10 years from
1996 to 2006 . So the study was conducted to assess the risk factors and outcome in the early neonatal period of babies who were asphyxiated at birth.

\section{Material and Method}

It was a retrospective study conducted at Neonatal Unit, TUTH. The study included the newborn babies delivered over a period of 1 year starting form $15^{\text {th }}$ February, 2007 to $14^{\text {th }}$ February, 2008. Criterion to diagnose birth asphyxia in the present study was having Apgar score $\leq 6$ at 1 minute of birth. Out of 3986 total deliveries, only term babies of $\geq 37$ weeks who had Apgar score of $\leq 6$ at 1 minute of birth were included. Apgar score of $4-6$ and $<3$ were defined as moderate and severe asphyxia respectively. Preterm babies and babies with congenital anomalies were excluded from the study. Details of delivery, antenatal and intrapartum factors and the neonatal data were pooled from perinatal database and hospital records. 


\section{Results}

Among 3594 live term babies, 327 babies had Apgar score $\leq 6$ at 1 minutes of birth. Sixty one percent $(61 \%)$ were males and thirty nine percent $(39 \%)$ were females. The mean birth weight was $3010+476$ grams. Seventy six percent $(76 \%)$, twenty percent $(20 \%)$ and four percent $(4 \%)$ of these babies were born by normal vaginal delivery, caesarian section and by instrumental delivery (vacuum or forceps) respectively. Of the asphyxiated babies, eighty five percent $(85 \%)$ had moderate and fifteen percent $(15 \%)$ had severe asphyxia at 1 minute of birth. At 5 minutes of birth, only ninteen percent (19\%) had moderate and one and a half percent $(1.5 \%)$ had severe asphyxia. Eighty five babies $(26 \%)$ required neonatal admission. Of the admitted babies, 25 babies developed HIE out of which sixty two percent $(62 \%)$ had stage II and thirty eight (38\%) had stage I according to Sarnat and Sarnat classification. Ninty two percent $(92 \%)$ of these babies were discharged six percent $(6 \%)$ died and two percent $(2 \%)$ left against medical advice.

Regarding risk factors, antenatal factors were identified in seven percent $(7 \%)$ of the asphyxiated babies and pregnancy induced hypertension was found to be most common factor (Figure 1) Intrapartum risk factors were seen in fifty one percent $(51 \%)$ and the major risk was due to meconium stained liquor which was found in two third of the asphyxiated babies.

Table 1: Intrapartum Risk Factors .

\begin{tabular}{|l|c|c|}
\hline \multicolumn{1}{|c|}{ Risk factors } & No. & $\begin{array}{c}\text { Percentage } \\
\text { \% }\end{array}$ \\
\hline Meconium stained liquor & 109 & 65 \\
\hline Fetal heart abnormality & 29 & 17 \\
\hline Non - vertex presentation & 16 & 10 \\
\hline $\begin{array}{l}\text { Prolong rupture of } \\
\text { membrane( }>\text { 18hours) }\end{array}$ & 14 & 8 \\
\hline
\end{tabular}

When comparing asphyxiated and non-asphyxiated babies, it was seen that intrapartum risk factors like meconium stained liquor, non vertex presentation, and fetal heart rate abnormality accounted for four fold risk for asphyxia. Maternal disease conditions like heart diseases, asthma increased the risk by two folds. However pregnancy related complications like pregnancy induced hypertension, pre-eclamptic toxemia, and gestational diabetes mellitus showed somewhat protective role against asphyxia. (Table: 2 )
Fig. 1: Pregnancy Related Maternal Risk Factors.

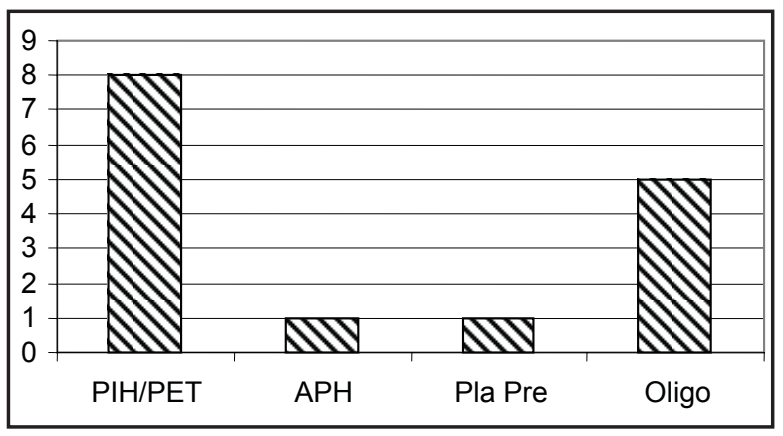

\section{Discussion}

Several studies have attempted to evaluate the incidence of asphyxia and its risk factors. The reported incidence of asphyxia amongst live born neonates varied from 1-10\%, ${ }^{4,5,6,7,8,9}$ In the present study using an Apgar score of $\leq 6$ at 1 minute of birth in an infant with or more than 37 week of gestation and the incidence was found to be nine percent $(9 \%)$. The variation observed due to the different definition of asphyxia that have been adopted by different authors; like Apgar score at 1 or 5 minute, duration of resuscitation, breathing effort at 1 minute. Although the Apgar score has been criticized because it does not accurately identify or predict subsequent neurodevelopmental outcome of newborn infants, it is still the most feasible and practical to perform in the delivery system. Therefore, until more useful index for assessing neonates is developed, the 5 minute Apgar score, is still valid and a rapid index for assessing the effectiveness of resuscitative efforts and the vitality of the infant. ${ }^{10}$ Here, in the present study, 1 minute Apgar was considered so as to focus on the condition of the newborn immediately after birth and its associated risk factors.

In the present study, seven percent $(7 \%)$ of the pregnancies were high risk which is comparable with several studies that have shown ten to twenty percent (10-20\%) pregnancies are considered high risk that include severe cardiac, pulmonary, circulatory problem and diabetes mellitus. ${ }^{11,12,13,14}$

Regarding intrapartum risk factors, meconium stained liquor was the most frequently associated with asphyxia accounting for sixty five percent $(65 \%)$ of the asphyxiated babies. Similar study by David R Hall et al has also found that among the asphyxiated babies, forty seven percent $(47 \%)$ had meconium stained liquor during labour. ${ }^{15}$

Table 2: Comparison between Asphyxiated and Non-Asphyxiated babies.

\begin{tabular}{|l|c|c|c|}
\hline & $\begin{array}{c}\text { Asphyxiated } \\
(\mathbf{n - 3 2 7})\end{array}$ & $\begin{array}{c}\text { Non-Asphyxiated } \\
(\mathbf{n - 3 2 6 7 )}\end{array}$ & Odds ratio \\
\hline Maternal diseases & 6 & 39 & 2.08 \\
\hline Pregnancy related complications & 15 & 192 & 0.7 \\
\hline Intrapartum Risks & 168 & 662 & 4.0 \\
\hline
\end{tabular}


In the present study, the risk of asphyxia was found to be four times with intrapartum risk factors like nonvertex presentation, meconium stained liquor, fetal heart rate abnormality, prolong rupture of membrane. Earlier studies have reported a 5 to 12 times risk of asphyxia with toxemia of pregnancy. ${ }^{8,9}$ However, in the current study there seems no difference with asphyxiated and non-asphyxiated babies whose mothers had pregnancy related complications like pregnancy induced hypertension and gestational diabetes mellitus. This might be due to regular follow up of these mothers and early interventions. Of these babies seventy percent $(70 \%)$ of the babies were born by cesarean section.

Of the admitted babies twenty nine percent (29\%) developed HIE which is comparable with other studies in which they have also found the incidence of HIE to be around 30\% in babies born with low Apgar score. ${ }^{16,17}$ Although Apgar score alone is weak marker of asphyxia, study by Sitthivuddhi $\mathrm{F}$ et $\mathrm{al}^{17}$ has shown that Apgar score of 3 or less at 5 minute is highly indicative of severe asphyxia and predictive of HIE and Neonatal mortality.

In summary, early identification and close monitoring of high risk mothers, maintaining partograph during labor and augmentation and early intervention, if required, will help to reduce mortality and morbidity associated with asphyxia.

\section{References}

1. Leviton A, Nelson KB. Problems with Definitions and Classifications of Newborn Encephalopathy. Pediatr Neurol 1992; 8(2):85-90.

2. Snyder EY, Cloherty JP. Perinatal Asphyxia. In: Cloherty JP, Stark AR, Editors. Amnual of Neonatal Care, 4rth ed.philadelphia: Lippincott-williams \& Wilkins; 1998.515-523.

3. State of the World's Newborn: Nepal Saving Newborn Lives. Save the Children July 2002.

4. Bhargava SK, BAtra A, Sen Gupta, Das SK. Study of Asphyxia Neonatarum. J Obstet Gynecol India 1988; 38: 162-166.

5. MAvDonald HM, Mulligan JC, Allen AC, Taylor PM.Neonatal asphyxia. In: Relationship of Obstretic Complications to Neonatal Mortality in 38,405 Consecutive Deliveries. J Pediatr 1980, 65:898-902.
6. Boo NY, Lye MS. Factors Associated with Clinically Significant Perinatal Asphyxia in Malaysian Neonates: A Case Controlled Study. $J$ Trop Pediatr 1992, 38:284-289.

7. Nathoo K J, Chimbra THK, Mtimavalye LAR. Mortaltiy and Immediate Morbidity in Term Babies with Low Apgar Scores (Zimbabwe). Ann Trop Pediatr 1990, 10:239-244.

8. Singh M, Paul VK, Deorari AK. Epidemiological Correlates, Early Clinical Features and Sequele of Perinatal Hypoxia. Indian Council of Medical Research Report, New Delhi, 1992.

9. Daga AS, Daga SR, Patole SK. Risk Assessment in Birth Asphyxia. J Trop Pediatr 1990, 36:34-39.

10. Casey BM, McIntire DD, Lnevo KJ. The Continuing Value of the Apgar Score for the Assessment of Newborn Infants. N Eng J Med 2001; 344;467-71.

11. Baloch R, Abasi KA, Malik B. Perinatal Mortality: A Hospital Based Survey. Pak J Obstet Gynaecol 1996;9(2,3):32-5.

12. Blair E, Stanley F. Aetiological Pathways to Spastic Cerebral Palsy. Paediatr Perinat Epidemilo. 1993; 7(3):302-317.

13. Coorsen EA, Msale ME, Duffy LC. Multiple Minor Malformations as a Marker of Prenatal Aetiology of Cerebral Palsy. Dev. Med Child Neurol. 1991; 33(8): 730-6.

14. HagbergG, Hagberg B, Olow I. The Changing Panaroma of Cerebral Palsy in Sweden 19541970, III : The Importance of Foetal Deprivation of Supply.Acta Paediatr Scand. 1976; 65(4): 4038.

15. Hall DR, Smith M, Smith J. Maternal Factors Contributing to Asphyxia Neonatorum. Journal of Tropical Pediatrics 1996 42(4):192-195; doi:10.1093/tropej/42.4.192

16. Shah GS, Singh R, Das BK. Outcome of Newborns with Birth Asphyxia. J Nepal Med Assoc. 2005 Apr-Jun; 44(158):44-6.

17. Sitthivuddhi F, Pramot P, Pimorlat T; Risk Factors Hypoxic-Ischemic Encephalopathy in Asphyxiated Newborn Infants. J Med Assoc Thai 2006; 89(3): 322-8. 